\title{
Mikroplastiklerin (MP) Sucul Organizmalar Üzerindeki Risk Profillerinin Değerlendirilmesi
}

\author{
Figen Esin KAYHAN
}

Marmara Üniversitesi, Fen Edebiyat Fakültesi, Biyoloji Bölümü, İstanbul

\section{* fekayhan@marmara.edu.tr}

Öz: Bu derlemenin amacı, sucul çevredeki mikroplastiklerin (MP) bazı deniz organizmaları ve insan sağlığı üzerine sebep olduğu sağlık risklerinin değerlendirilmesidir. Mikroplastikler deniz ortamlarında bulunan küçük plastik parçacıklardır. Ayrıca ağır metaller, pestisitler ve çevresel kirleticiler de dahil olmak üzere ortamdan çeşitli kimyasal kalıntıları absorbe edebilirler. Bu derleme çalışmasında plastik ve mikroplastiklerin bazı sucul organizmalar ve sucul ekosistem üzerindeki olumsuz etkileri özetlenmiştir.

Anahtar Kelimeler: Mikroplastikler, Sucul organizmalar, Sucul kirlenme

\section{The Evaluation of Risk Profiles of Microplastics (MP) on Aquatic Organisms}

\begin{abstract}
The aim of this review is to investigation of the health risks caused by microplastics on humans and some aquatic organisms in aquatic environment. Microplastics are small plastic particles present in marine environments. Besides they can absorb various chemical residues from the surrounding environment, including heavy metals, pesticides and environmental pollutants. In this review summarizes the negative effects of plastic and microplastics on some aquatic organisms and aquatic ecosystems.
\end{abstract}

Keywords: Microplastics, Aquatic organisms, Aquatic pollution

\section{Giriş}

Dünya ölçeğinde y1lda 250 milyon ton plastik üretilmektedir. $\mathrm{Bu}$ nedenle plastik kullanımının baş edilmesi zor boyutlarda bir problem olduğu artık bilinen bir gerçektir (Plastics Europe, 2015). Plastikler, petrol ve türevlerinden elde edilen sentetik organik polimerler olarak tanımlanabilir. Plastikler çok fazla miktarda üretilmekle birlikte, tek kullanımlık olmaları, yavaş çözünmeleri, doğal yollarla ortadan kaybolmamaları gibi özellikleri nedeniyle toprak, akarsular, göller ve denizler gibi doğal yaşam alanlarında birikerek zarar vermektedirler (Bordos ve ark.. 2019; Yuan ve ark., 2019). Endüstriyel gelişimle birlikte plastiklerin hayatımıza kattığı faydalar elbetteki yadsınamaz ancak kalıcı zararlarından etkilenmemekte elde değildir. Özellikle yaban hayatı üzerinde çok önemli bir tehdit unsurudur. Farklı boyutlardaki plastik parçalarını besin zannederek yutan her türden omurgasız, balık, balık larvaları, sürüngen, kuş ve memeli organizmalar yaşamlarını 
kaybetmektedir (Perez-Venegas ve ark., 2018; Renzi ve ark., 2018). Kuzey kutbu fok türlerinden olan Kuzey Kürklü Fokta (Callorhinus ursinus) mikroplastik maruziyetinin araştırıldığ 1 bir çalışmada fokların dışkıları analiz edilmiştir. Dışkı analizi sonuçlarına göre Kuzey kürklü Foku'nun Doğu Pasifik Okyanus'u menzili boyunca mikro plastiklere maruz kaldığ rapor edilmiştir (Donohue ve ark., 2019). Mikroplastiklerin (MP) sucul canlilar tarafindan yutulması canlıların doku ve organlarına fiziksel zararlarda vermektedir (FAO, 2016; GESAMP, 2016).

Denizlerde yaşayan organizmalar ile mikroplastiklerin etkileşimi ve besin zincirindeki bulunuşları

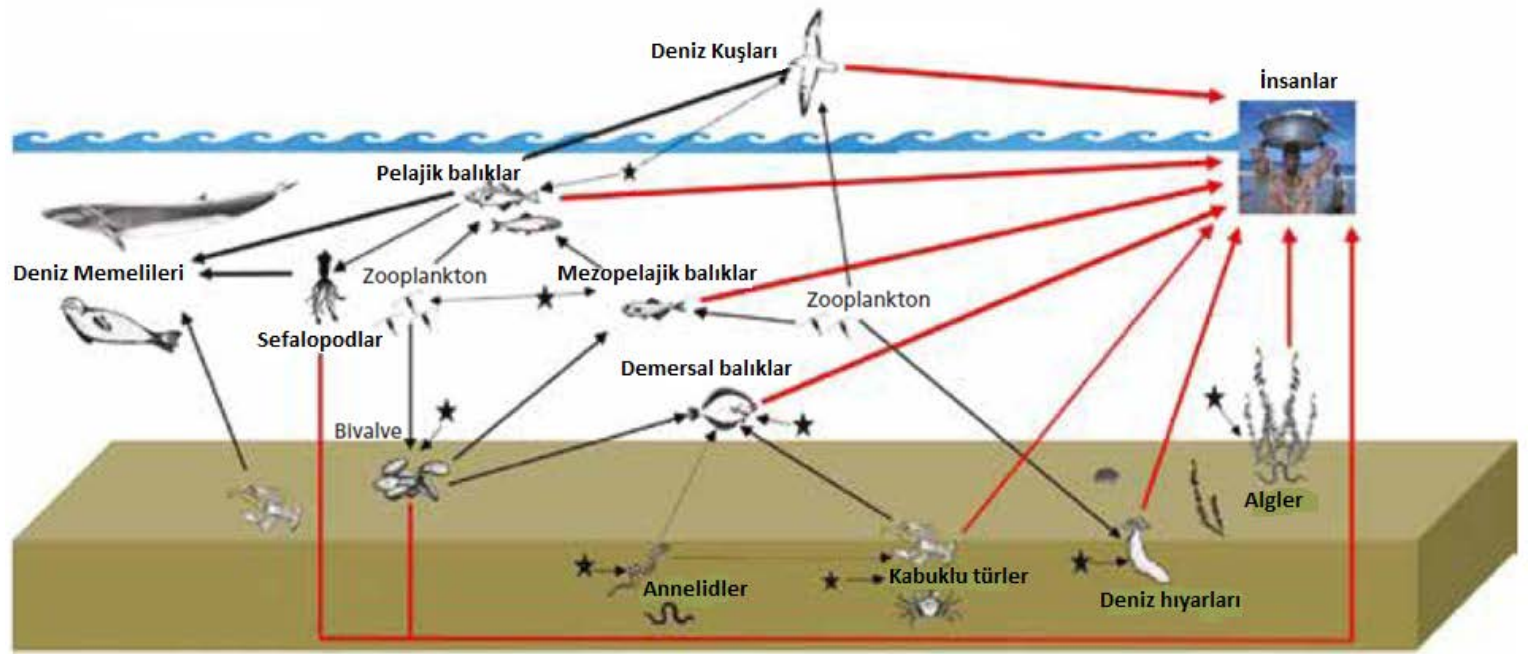

Şekil 1. Denizlerde yaşayan organizmalar ile mikroplastiklerin etkileşimi ve besin zincirindeki bulunuşları (Siyah yıldızlar mikroplastik (MP) parçacıklarını temsil eder ve siyah noktalı oklar organizma ile parçacık arasında gözlenen etkileşim yönünü göstermektedir. Siyah oklar MP’lerin dolaylı yolla alımını gösterir. Kırmızı oklar, sucul organizmaların yutulmasının ardından MP’lerin potansiyel yolunu göstermektedir).

Sucul ortamda bulunan mikroplastik parçacık çeşitleri fiber, polyester ve naylon olarak sıralanabilir. Naylon, her ne kadar formülasyonları farklı olsa da endüstriyel anlamda hayatımıza giren ilk plastik ürün olarak sayılabilir. Plastikler, polietilen yapıdadır ve sadece karbon ve hidrojen atomlarından oluşurlar. Naylon ise, karbon, hidrojen ve azot atomlarından oluşur. Günlük hayatımızda hemen her eşyada sıklıkla kullanmaktayı. $\mathrm{Bu}$ malzemeler yüksek moleküler ağırlıklı malzemelerdir ve biyolojik olarak parçalanamadıkları için çevrede son derece kalıcıdırlar. Plastik atıklar doğada uzun yıllar süren yavaş bozunmaları sirasinda fotokimyasal ve mekanik süreçlere bağlı olarak mikroskobik boyuttaki parçalara ayrılırlar. Mikroplastikler (MP) kavramı işte burada ortaya çıkmaktadır. NOAA (National 
Oceanic and Atmospheric Administration) tanımına göre 5 mm'den daha ufak olan plastik parçaları "Mikroplastikler" olarak kabul edilir (NOAA, 2008). MP'ler belirli bir şekil veya boyutta bulunmazlar. Mikroplastikler, boyut, şekil, renk, kimyasal bileşim, yoğunluk ve diğer bazı özelliklere göre değişen çok heterojen bir partikül topluluğunu içerir. Genellikle amorf şekillerde olan mikroplastik parçacıklar küresel, silindirik, uç kısımları yuvarlak, oval ve çeşitli boyutlarda lifçikler formunda olabilirler (Yurtsever, 2015). MP’ler, birincil ve ikincil olarak iki gruba ayrılırlar. Birincil mikroplastikler, mikroskobik boyutlardaki polietilen mikroboncuklardir. Bunlar genellikle tüketici farkında olmasa da diş macunu, peeling kremleri gibi kozmetik ürünlerde ve deterjanlarda bulunurlar. İkincil mikroplastikler ise büyük plastik parçalarının güneş 1şığı, su ve rüzgâr gibi çevresel etkilerle aşınması ve küçük boyutlara ufalanması sonucu ortaya çıkan mikroplastiklerdir (Gregory, 2009; Digka ve ark., 2018). Sirasıyla makro boyuttaki plastikler önce mikroplastiklere, daha sonra parçalanmanın devam etmesiyle nanoplastiklere dönüşürler (Denizli ve Yavuz, 2017). MP'ler atık suların arıtmas1 sirasinda filtrelenmezler ve genellikle doğrudan deniz, göl ve nehir gibi tatlı ve tuzlu su ortamlarına salınırlar. 2011 yilında yapılan bir araştırmada sabun tüketimine bağlı olarak kanalizasyona dökülen MP miktarının kişi başı günlük 2.4 mg olduğu rapor edilmiştir (Cole ve ark., 2015; Faggio ve ark., 2018). Mikroplastik parçacıklar optik ve elektron mikroskopları ile incelenmelerinin yanında Raman ve FTIR (Fourier-transform infrared spectroscopy Fourier dönüşümlü kızılötesi spektroskopisi) spektrofotometreleri ile tanımlanmaları mümkündür (Yurtsever, 2015).

\section{Mikroplastiklerin Toksik Etkileri}

Plastik polimerler farklı toksisite dereceleri gösterebilir. $\mathrm{Bu}$ nedenle mikroplastiklerin olumsuz etkileri plastik türüne, kimyasal bileşimine ve plastik afiniteye sahip kimyasal kirleticilerin emilimine de bağlıdır (Zhu ve ark., 2019). Örneğin; Rochman ve ark. (2013), PET veya polietilenden ziyade Polivinilklorür (PVC) veya Polistiren'e (PS) maruz kalma nedeniyle tatlı su istiridyelerinde (Corbicula fulminea) daha fazla histolojik anormallik tespit etmişlerdir. Bununla birlikte, yapılan bazı araştırmalarda mikroplastiklerin Oryzias latipes (Japon Pirinç Balığı) (Rochman ve ark., 2013), Zebra balığ (Danio rerio) (Khan ve ark., 2015; Lu ve ark., 2016) ve Dicentrarchus labrax'da (Avrupa Levrek balığı) (Peda ve ark., 2016) su ortamı içindeki kimyasal kirleticilerin toksik etkisini arttırdığg gösterilmiştir. Sucul organizmalar mikroplastikleri öncelikle sindirim sistemlerinde biriktirirler. Bazı sucul omurgasız türler açısından MP'lerin 
vücuda alınması sadece beslenme yoluyla 2018b).

olmayabilir (Li ve ark., 2018a; Li ve ark.,

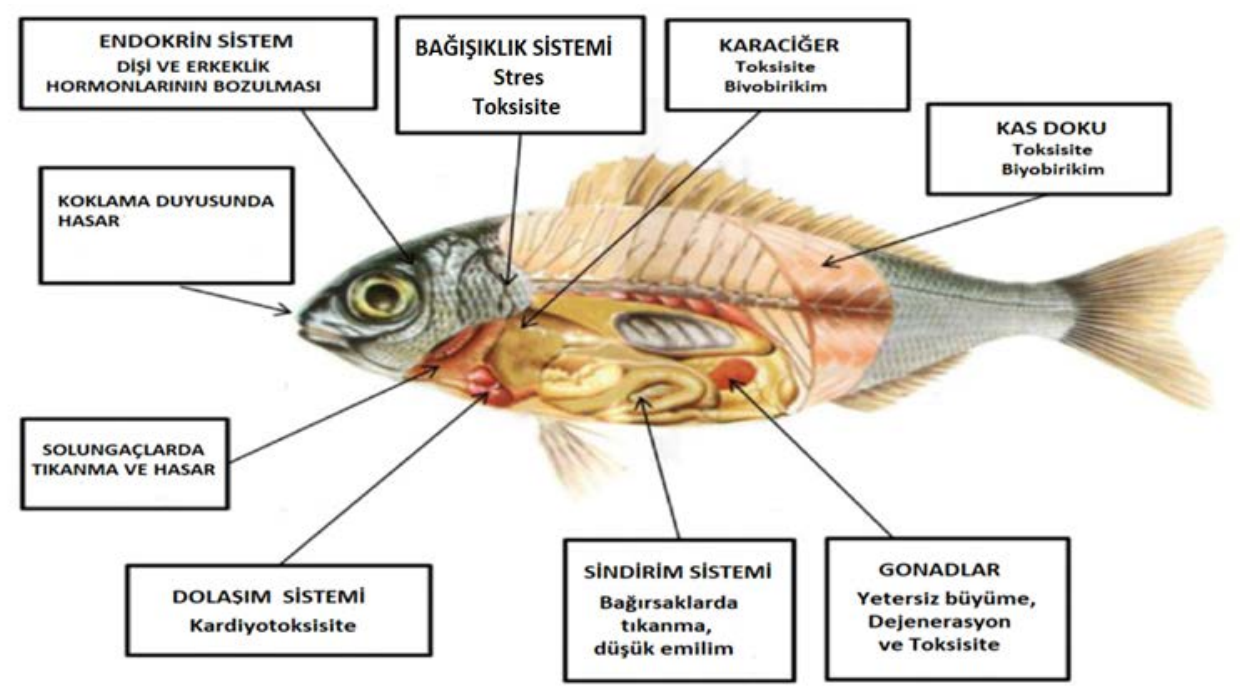

Şekil 2. Mikroplastiklerin balık üzerindeki başlıca etkileri

Bazı yengeçlerin solungaçlarında mikroplastik parçacıklar bulunmuştur. MP’ler denizlerdeki çevresel kirleticiler de dahil olmak üzere çevredeki tüm kimyasal maddeleri emebilen bir polimer ve katk1 kokteyli oluştururlar. Çok küçük boyutları $(<5 \mu \mathrm{m})$ göz önüne alındığında, MP’ler çok çeşitli deniz organizmaları tarafindan besin zannedilerek yutulmaktadir (Rummel ve ark., 2016). Okyanuslarda, denizlerde ve tatlı sulardan avlanan çok sayıda balık türünde mikroplastiklerin varlığ1 gözlenmiştir (Alomar ve ark., 2017; Bessa ve ark., 2018; Jabeen ve ark., 2017; Morgana ve ark., 2018; Pazos ve ark., 2017). Buna ek olarak, bazı araştırmacılar, kontrollü laboratuar koşullarında balıklar ve larvalar tarafindan mikroplastik alımı sırasında toksik bileşiklerinde kolayca taşındıklarını rapor etmişlerdir. Pozo ve ark. (2019) Şili'de yaptıkları çalışmalarında altı ekonomik balık türünün mide ve bağırsak içeriğinde çeşitli mikroplastikleri tanımlamış ve kategorize etmişlerdir. Farklı trofik seviyelerindeki balıklar okyanus ve kıyı habitatlarından elde edilmiştir. Kıyı türlerinde (\%71) okyanus türlerine (\%29) oranla daha fazla mikrofiber özellikte mikroplastik parçacık bulduklarını rapor etmişlerdir. Ekonomik değere sahip altı yumuşakça türünde (Mytilus galloprovincialis, Ruditapes decussatus, Crassostrea gigas, Hexaplex trunculus, Bolinus brandaris, Sepia officinalis) yapilan bir mikroplastik parçacık araştırmasında organizmaların biyoyararlanımı ve besin zincirindeki tüketici risklerini belirlenmeye çalışılmış ve elde edilen MP tipleri, sırasıyla 
lifler, fragmanlar ve filmler halinde olduğu ifade edilmiştir. En yaygın görülen lifler ise genellikle polietilen ve polipropilen türü polimerlerdir. Tunus'un Bizerte Lagünü bölgesinde yapılan bir araştırmada, bölgede yaşayan yumuşakça türlerinde mikroplastik parçacıkları açısından yüksek riskler olduğu rapor edilmiştir (Abidli ve ark., 2019). Hong Kong'un doğu kıyılarında yapılan bir araştırmada da 30 adet çiftlik kefali ile 30 adet doğal deniz kefal balığının sindirim sistemlerindeki mikroplastik oranları araştırılmış ve doğal balıklarda daha fazla MP bulunmuştur. Ayrıca balık büyüklüğü ile doğru orantılı bir artış oranı bulunduğu rapor edilmiştir (Cheung ve ark., 2018). Kuzey Buz Denizi'nin güney sahillerinde yapılan bir araştırmada Crangon crangon türü kahverengi karideslerdeki mikroplastik parçacık miktarı incelenmiş olup karides örneklerinin \%63'ünde farklı boyutlarda sentetik lifler tespit edilmiştir (Devriese ve ark., 2015; OSPAR, 2015). Plastik atıklar; son zamanlarda ortaya çıkan kirletici maddeler olarak kabul edilmektedir ve dünya genelinde deniz biyolojik çeşitliliği açısından büyük bir risk oluşturmaktadır. Mikroplastikler deniz biyotası ve ekosistem için büyüyen bir tehdittir. Organizmalar için mikroplastik yutmayla ilişkili riskler, yalnızca malzemenin kendisinden değil, aynı zamanda çevre kirletici maddelerini deniz suyundan emme ve konsantre etme ve daha sonra bunları gida zincirleri yoluyla transfer etme kabiliyetinden de kaynaklanmaktadır. Ayrıca, mikroplastikler ekolojik süreçleri etkileyebilir (Guzzetti ve ark., 2018).

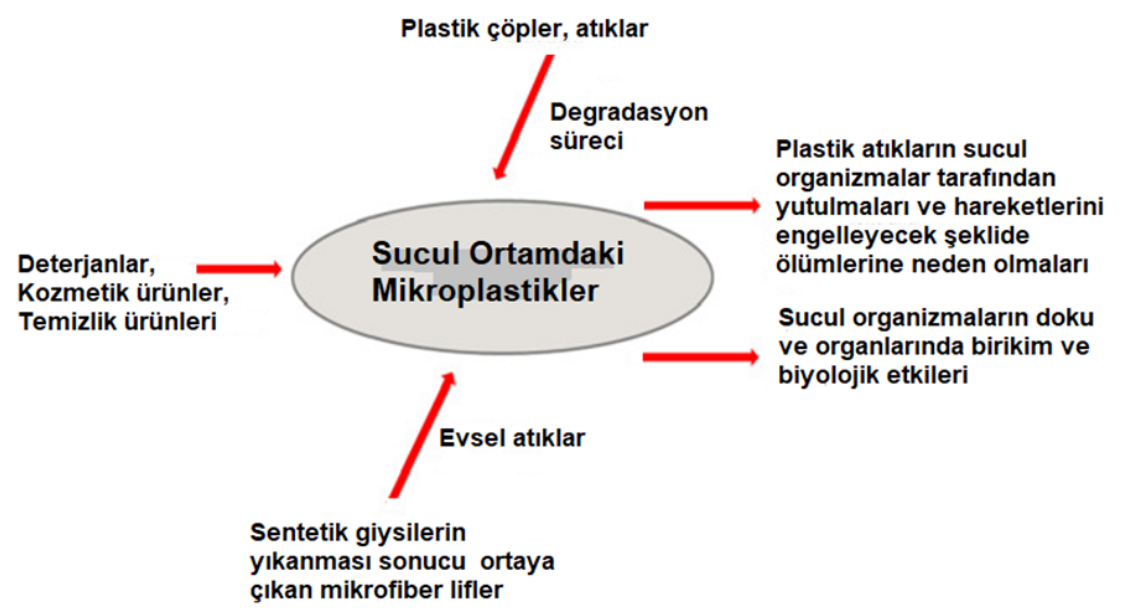

Şekil 2. Mikroplastiklerin sucul ekosistemdeki akıbeti

2016 yılında Akdeniz kıyılarımızda her ay yapılan örnekleme çalışmasında ekonomik öneme sahip ve aralarında Dentex dentex, Liza aurata, Mullus barbatus, 
Sardina pilchardus, Scomber japonicus, Trachurus mediterraneus, Trigla lucerna gibi demersal, pelajik ve bentopelajik alanda yaşayan organizmaların da olduğu 28 türe ait toplam 1137 balığın yarısından fazlasının sindirim siteminde mikroplastik parçacık bulunduğu rapor edilmiştir. $\mathrm{Bu}$ balıkların sindirim sistemlerinde en fazla bulunan parçacık tipi genellikle çamaşır makinalarından geldiği düşünülen tekstil fiber olduğu görülmüştür (Guven ve ark., 2017). 2016 y1lında ülkemizde 9 milyon ton plastik malzeme üretilmiş olup ülkemizde her yıl yaklaşık yarım milyon ton plastik atık olarak çevreye atılmaktadır. Dünyada olduğu gibi ülkemizde de denize ulaşan katı atıkların \%80'inden fazlasını plastikler oluşturuyor (Aytan ve ark., 2016). Katı atıkların doğal yollarla kendi halinde parçalanmasının yanı sıra denizdeki mikroplastiklerin en önemli kaynağı atık su tesisleri olduğu kabul edilmektedir (Koelmans, 2015; Waite ve ark., 2018). Deşarj edilen kentsel atık suların içinde özellikle çamaşır makinelerinden gelen sentetik elyaf ve temizlik malzemelerinden kaynaklanan mikroplastik ve mikroboncuk parçacıkları bulunmaktadır. Bu nedenle atık sulardan mikroplastiklerin giderilmesi işlemlerinde atık su tesisleri dahi etkisiz kalmaktadır. Mikroplastikler dahil tüm plastik ürünlerin deniz ekosistemlerindeki kirlilik seviyesinin takip edilmesi ve neden olduğu zararlı çevresel etkilerin araştırılması
Avrupa Birliği ülkelerinde uzun süredir uygulanmakta olan yasal bir zorunluluktur (Farrell ve Nelson, 2013; Provencher ve ark., 2018). 2014'te dünya denizlerinde suda sürüklenir vaziyette tüm plastiklerin sayısının altı trilyon ton olduğu ve bunun 4.85 trilyon tonunun mikroplastikleri oluşturduğu rapor edilmiştir (Prokic ve ark., 2019). Birincil mikroplastiklerin endüstride kullanımı ve dağıtımını sınırlandırmaya yönelik bazı kanun düzenlemeleri yapılmaktadır. Örneğin; Amerika Birleşik Devletleri, Temmuz 2018'den itibaren mikroplastik ürünlerin imalatını yasaklamış bulunmaktadır. Özellikle mikroplastik üretebilecek kozmetik ürünlerin satışını da kısıtlayacak yaptırımları en kısa zamanda yürürlüğe koyulması planlanmaktadır (UNEP, 2014). İngiltere ve Fransa'da yapılan bazı kanun düzenlemeleri ile mikroboncuk içeren kozmetik ve temizlik ürünlerinin satışları ve kullanımı yasaklanmıştır. Birçok Avrupa ülkesi ve Çin ve Avustralya'da plastik ve naylon poşet kullanımı yasaklanmıştır. Kanada, Almanya, İngiltere, Hollanda ve İrlanda'da poşetlerin kullanımı vergilendirilmiştir (Fendall ve Sewell, 2009; Cho ve ark., 2019). Mikroplastikler besin zincirinde üst trofik seviyelere kolayca taşınmaktadır. Üstelik trofik besin zinciri boyunca birikebilen mikroplastiklere çok sayıda çevreye zararlı ağır metaller, pestisitler ve bisfenol-A, gibi kimyasal maddeler de eklenir. Bentik zonda 
yaşayan balıklar başta olmak üzere mikroplastik parçacık tehlikesi gerçeğini göz filtrasyonla beslenen midye ve istiridyeler, ardı edemeyiz. Mikroplastikler genel olarak yengeçler ve çiftliklerde üretilen su deniz yaşamı içinde hem doğal türlerin hem ürünlerinde bile mikroplastik parçacıklara de kültür su ürünleri yetiştiriciliğinin rastlanmıştır (Avio ve ark., 2015a,b; Prokic ve ark., 2019). Literatüre bakıldığında MP'lerin varlığı ile ilgili yapılan araştırmalar sonucunda insanları da içine alan büyük riskler olduğu görülmektedir.

Sonuç: MP'lerin risk değerlendirmesi konusunda ülkemizde henüz az sayıda çalışma mevcuttur. Bu durum, mikroplastik riskinin gerçekçi bir şekilde anlaşılmasını engellemektedir. Giderek "plastik gezegen” olma yolunda ilerleyen dünyamı için boyutları "mikro" ama riskleri "mega" olan sağlığını ve gelişmesini olumsuz yönde etkileyebilir. $\mathrm{Bu}$ açıkça sadece sucul çevre için değil insan sağlığ 1 için de büyüyen ve gelecek adına tehlikeli bir sorundur. Gelecekte daha da fazla oranlarda olumsuz etkilerini gözlemleyeceğimiz mikroplastik kirliliği hakkında sucul organizmalarda görülebilecek potansiyel olumsuz risklerinin tam olarak belirlenmesi için daha kapsamlı araştırmaların yapılması gerekmektedir.

\section{Kaynaklar}

Abidli S, Lahbib Y, El Menif T (2019). Microplastics in commercial mollusks from the lagoon of Bizerte (Northern Tunisia). Marine Pollution Bulletin 142: 243-252.

Alomar C, Sureda A, Capco C, Guijarro B, Tejada S, Deudero S (2017). Microplastic ingestion by Mullus surmuletus Linnaeus, 1758 fish and its potential for causing oxidative stress. Environmental Research 159: 135-142.

Avio CG, Gorbi S, Milan M, Benedetti M, Fattorini D, D'Errico G, Pauletto M, Bargelloni L, Regoli F (2015a). Pollutants bioavailability and toxicological risk from microplastics to marine mussels. Environmental Pollution 198: 211-222.

Avio CG, Gorbi S, Regoli F (2015b). Experimental development of a new protocol for extraction and characterization of microplastics in fish tissues: first observations in commercial species from Adriatic Sea. Marine Environmental Research 111: 18-26.

Aytan U, Valente A, Senturk Y, Usta R, Esensoy Sahin FB, Mazlum RE, Agirbas E (2016). First evaluation of neustonic microplastics in Black Sea waters. Marine Environmental Research 119: 22-30.

Bessa F, Barría P, Neto JM, Frias JPGL, Otero V, Sobral P, Marques JC (2018). Occurrence of microplastics in commercial fish from a natural estuarine environment. Marine Pollution Bulletin 128: 575-584. 
Bordos G, Urbányi B, Micsinai A, Kriszt B, Palotai Z, Szabó I, Hantosi Z, Szoboszlay S (2019). Identification of microplastics in fish ponds and natural freshwater environments of the Carpathian basin, Europe. Chemosphere 216: 110-116.

Cheung LTO, Lui CY, Fok L (2018). Microplastic contamination of wild and captive Flathead Grey mullet (Mugil cephalus). International Journal of Environmental Research and Public Health 15: 597-601.

Cho Y, Shim WJ, Jang M, Han GM, Hong SH (2019). Abundance and characteristics of microplastics in market bivalves from South Korea. Environmental Pollution 245: 1107-1116.

Cole M, Lindeque P, Fileman E, Halsband C, Galloway TS (2015). The impact of polystyrene microplastics on feeding, function and fecundity in the marine copepod Calanus helgolandicus. Environmental Science \& Technology 49: 1130-1137.

Denizli A, Yavuz H (2017). Mikroplastikler ve Dünyamız. Tüba Günce 64: 9.

Devriese LI, Van der Meulen MD, Maes T, Bekaert K, Paul-Pont I, Frere L, Robbens J, Vethaak AD (2015). Microplastic contamination in brown shrimp (Crangon crangon, Linnaeus 1758) from coastal waters of the Southern North Sea and Channel area. Marine Pollution Bulletin 98: 179-187.

Digka N, Tsangaris C, Torre M, Anastasopoulou A (2018). Microplastics in mussels and fish from the Northern Ionian Sea. Marine Pollution Bulletin 135: 30-40.

Donohue MJ, Masura J, Gelatt T, Ream R, Baker JD, Faulhaber K, Lerner DT (2019). Evaluating exposure of northern fur seals, Callorhinus ursinus, to microplastic pollution through fecal analysis. Marine Pollution Bulletin 138: 213-221.

Faggio C, Tsarpali V, Dailianis D (2018). Mussel digestive gland as a model tissue for assessing xenobiotics: an overview. Science of the Total Environment 636: 220-229.

FAO (2016). The state of the worlds fisheries and aquaculture 4-10.

Farrell P, Nelson K (2013). Trophic level transfer of microplastic: Mytilus edulis to Carcinus maenas. Environmental Pollution 117: 1-3.

Fendall LS, Sewell MA (2009). Contributing to marine pollution by washing your face: microplastics in facial cleansers. Marine Pollution Bulletin 58: 1225-1228.

GESAMP (Group of Experts on the Scientific Aspects of Marine Environmental Protection) (2016). Sources, fate and effects of microplastics in the marine environment: part two of a global assessment. In: Kershaw, P.J., Rochman, C.M. (Eds.), (IMO/FAO/UNESCOIOC/UNIDO/WMO/IAEA/UN/UNEP/UNDP Joint Group of Experts on the Scientific Aspects of Marine Environmental Protection). Rep. Stud. GESAMP No. 93, (220 p).

Gregory MR (2009). Environmental implications of plastic debris in marine settingsentanglement, ingestion, smothering, hangers-on, hitch-hiking and alien invasions. Biological Sciences 364(1526): 2013-2025.

Guzzetti E, Sureda A, Tejada S, Faggio C (2018). Microplastics in marine organisms: Environmental and toxicological effects. Environmental Toxicology and Pharmacology 64: 164-171.

Guven O, Gokdağ K, Jovanovic B, Kıdeys AE (2017). Microplastic litter composition of the Turkish territorial waters of the Mediterranean Sea, and its occurrence in the gastrointestinal tract of fish. Environmental Pollution 223: 286-294. 
Jabeen K, Su L, Li J, Yang D, Tong C, Mu J, Shi H (2017). Microplastics and mesoplastics in fish from coastal and fresh waters of China. Environmental Pollution 221: 141-149.

Khan FR, Syberg K, Shashoua Y, Bury NR (2015). Influence of polyethylene microplastic beads on the uptake and localization of silver in zebrafish (Danio rerio). Environmental Pollution 206: 73-79.

Koelmans AA (2015). Modeling the role of microplastics in bioaccumulation of organic chemicals to marine aquatic organisms. A critical review. In: Marine Anthropogenic Litter 70: 309-324.

Li HX, Ma LS, Lin L, Ni ZX, Xu XR, Shi HH, Yan Y, Zheng GM, Rittschof D (2018a). Microplastics in oysters Saccostrea cucullata along the Pearl River estuary, China. Environmental Pollution 236: 619-625.

Li J, Green C, Reynolds A, Shi H, Rotchell JM (2018b). Microplastics in mussels sampled from coastal waters and supermarkets in the United Kingdom. Environmental Pollution 241: 35-44.

Lu Y, Zhang Y, Deng Y, Jiang W, Zhao Y, Geng J, Ding L, Ren H (2016). Uptake and accumulation of polystyrene microplastics in zebrafish (Danio rerio) and toxic effects in liver. Environmental Science \& Technology 50: 4054-4060.

Morgana S, Ghigliotti L, Estévez-Calvar N, Stifanese R, Wieckzorek A, Doyle T, Christiansen JS, Faimali M, Garaventa F (2018). Microplastics in the Arctic: a case study with sub-surface water and fish samples of Northeast Greenland. Environmental Pollution 242: 1078-1086.

NOAA (National Oceanic and Atmospheric Administration) (2008). Proceedings of the International Research Workshop on the occurrence, effects and fate of microplastic marine debris. In: Arthur C, Baker J, Bamford H. (Eds.), Technical Memorandum NOSOR\&R-30. University of Washington Tacoma, Tacoma, WA, USA September 9.11.

OSPAR (The Convention for the Protection of the Marine Environment of the North-East Atlantic) (2015). Coordinated Environmental Monitoring Programme (CEMP) Guidelines for Monitoring and Assessment of Plastic Particles in Stomachs of Fulmars in the North Sea area. Agreement 2015-03.

Pazos RS, Maiztegui T, Colautti DC, Paracampo AH, Gómez N (2017). Microplastics in gut contents of coastal freshwater fish from Río de la Plata estuary. Marine Pollution Bulletin 122 (1-2): 85-90.

Peda C, Caccamo L, Fossi MC, Gai F, Andaloro F, Genovese L, Maricchiolo G (2016). Intestinal alterations in European sea bass Dicentrarchus labrax (Linnaeus, 1758) exposed to microplastics: Preliminary results. Environmental Pollution 212: 251-256.

Perez-Venegas DJ, Seguel M, Pavés H, Pulgar J, Urbina M, Ahrendt C, Galbán-Malagón C (2018). First detection of plastic microfibers in a wild population of South American fur seals (Arctocephalus australis) in the Chilean Northern Patagonia. Marine Pollution Bulletin 136: 50-54.

Plastics Europe (2015). Plastics the facts 2015: An analysis of European latest plastics production, demand and waste data. http://www.plasticseurope.org/documents/document/20151216062602plastics_the_facts_2015_final_30pages_14122015.pdf

Pozo K, Gomez V, Torres M, Vera L, Nunez D, Oyarzun P, Mendoza G, Clarke B, Fossi MC, Baini M, Pribylova P, Klanova J (2019). Presence and characterization of MPs in fish of 
commercial importance from the Biblio region in the central Chile. Marine Pollution Bulletin 140: 315-319.

Prokic MD, Radovanovic TB, Gavric JP, Faggio C (2019). Ecotoxicological effects of microplastics: Examination of biomarkers, current state and future perpectives. Trends in Analytical Chemistry 111: 37-46.

Provencher JF, Vermaire JC, Avery-Gomm S, Braune BM, Mallory ML (2018). Garbage in guano? Microplastic debris found in faecal precursors of seabirds known to ingest plastics. Science of Total Environment 644: 1477-1484.

Renzi M, Guerranti C, Blaskovic A (2018). Microplastic contents from maricultured and natural mussels. Marine Pollution Bulletin 131: 248-251.

Rochman CM, Hoh E, Kurobe T, Teh SJ (2013). Ingested plastic transfers hazardous chemicals to fish and induces hepatic stress. Scientific Reports 3: 32-63.

Rummel CD, Loder MG, Fricke NF, Lang T, Griebeler EM, Janke M, Gerdts G (2016). Plastic ingestion by pelagic and demersal fish from the North Sea and Baltic Sea. Marine Pollution Bulletin 102: 134-141.

UNEP (United Nations Environment Programme) (2014). Plastic waste causes financial damage of US\$13 billion to marine ecosystems each year as concern grows over microplastics. $\quad$ http://www.unep.org/newscentre/default.aspx?DocumentiD1/42791 \&articleiD $1 / 410903$

Waite HR, Donnelly MJ, Walters LJ (2018). Quantity and types of microplastics in the organic tissues of the eastern oyster Crassostrea virginica and Atlantic mud crab Panopeus herbstii from a Florida estuary. Marine Pollution Bulletin 129: 179-185.

Yuan W, Liu X, Wang W, Di M, Wang J (2019). Microplastic abundance, distribution and composition in water, sediments, and wild fish from Poyang Lake, China. Ecotoxicology and Environmental Safety 170: 180-187.

Yurtsever M (2015). Mikroplastiklere genel bir bakış. Dokuz Eylül Üniversitesi Mühendislik Fakültesi. Fen ve Mühendislik Dergisi 17(50): 68-83.

Zhu J, Zhang Q, Li Y, Tan S, Kang Z, Yu X, Lan W, Cai L, Wang J, Shi H (2019). Microplastic pollution in the Maowei Sea, a typical mariculture bay of China. Science of the Total Environment 658: 62-68. 